\title{
EXPERIMENTAÇÃO E DESENVOLVIMENTO DA ARGUMENTAÇÃO CIENTÍFICA EM AULAS DE QUÍMICA DO ENSINO BÁSICO
}

Yasmin Letícia Nunes Araujo Juliana Milanez Leonardo Maciel Moreira

\section{Introdução}

Este trabalho é fruto da pesquisa desenvolvida para a dissertação de mestrado da autora, que nasce da inquietação acerca da utilização da experimentação em aulas de química a partir da utilização de roteiros experimentais pré-estabelecidos condizentes com uma concepção reprodutiva do "passo a passo" experimental, meramente executado e observado pelos estudantes. A intenção é favorecer uma participação mais ativa por parte do estudante e contribuir com a disponibilização de outras ferramentas educacionais para os docentes. Partindo da nossa própria vivência formativa $\mathrm{e}$ profissional, intencionamos um ensino mais dinâmico, que oportunize reflexões sobre os conhecimentos científicos, sua relação com o cotidiano, com a criação de hipóteses, argumentação e solução de problemas, 
contribuindo para uma formação mais crítica e questionadora dos estudantes.

\section{Experimentação e argumentação no ensino de ciências}

Sobre o uso da experimentação para o ensino de ciências, Galiazzi et al (2001) afirmam que há um consenso entre professores e pesquisadores sobre sua importância e que muito se tem estudado e pesquisado a respeito da experimentação (GALIAZZI et al, 2001 apud WELLINGTON, 1998; FRASER; TOBIN, 1998; GABEL, 1994). Nesse mesmo sentido, Suart (2014) cita que a experimentação no ensino de química é tema constante nas salas de aulas, nas conversas entre professores da disciplina, em congressos e em revistas da área, seja por sua contribuição para o processo de ensino e aprendizagem ou pelas dificuldades encontradas para sua aplicação e desenvolvimento (SUART, 2014 p. 63).

Apesar do avolumado contexto das pesquisas sobre experimentação, nossa prática cotidiana nos permite concordar com Galiazzi et al (2001, p. 250) ao afirmar que "a vivência nas escolas, nos mostra que as atividades experimentais são pouco frequentes". Schwahn e Oaigen (2008) apresentam alguns fatores que levam professores e futuros professores a se afastarem do uso da experimentação: 
A falta de preparo adequado dos futuros professores durante seus cursos de licenciatura, a falta de articulação entre teoria e prática, a falta de estrutura nos laboratórios das escolas, visão simplista dos professores e alunos no uso da experimentação, podem ser considerados fatores que afastam professores e alunos de aulas experimentais (SCHWAHN E OAIGEN, $2008 \mathrm{p}$. 153).

Além disso, a investidura em promover, a partir de problemas experimentais, o desenvolvimento de habilidades cognitivas, raciocínio lógico e processos argumentativos ainda é pouco explorada. Em geral o que se observa por meio do levantamento de leituras e pesquisas é o uso da experimentação ainda pautada em concepções tradicionalistas que privilegiam o tecnicismo e a comprovação de teorias vistas em sala de aula, tal qual enfatizado por Suart (2014):

Tais atividades são, geralmente, realizadas de forma isolada do contexto de ensino, utilizadas após o desenvolvimento de determinado conteúdo em sala de aula, a fim de que o aluno verifique ou comprove o que foi discutido. É apresentada em roteiros preestabelecidos, [...] para que o aluno cumpra passo a passo o que deve ser executado, de forma a evitar erros. [...] como se o experimento tivesse sempre que dar certo, ou seja, como se a ciência nunca errasse. (SUART, 2014 p.72) 
Segundo Barberá e Valdes (1996), a inserção, nas instituições de ensino, de práticas experimentais para o ensino de ciências pautadas nessa visão indutivista do método científico vem sendo criticada e desacreditada no meio acadêmico científico, mas segue distante de ser erradicada do mundo do ensino de ciências.

Apesar da dificuldade e da resistência em se alterar essa práxis docente, existem proposições e metodologias, em detrimento às tradicionais, que visam contribuir para o desenvolvimento de atividades experimentais investigativas, com caraterísticas dialógicas e participativas, que movimentam as habilidades cognitivas dos estudantes, contemplando aspectos formativos que favorecem a criticidade, a criatividade, a argumentação e o raciocínio lógico. Destacamos aqui duas proposições que estudamos para o desenvolvimento da pesquisa.

A primeira proposta é a metodologia conhecida como P.O.E - Predizer, Observar, Explicar. Esse método foi muito utilizado inicialmente em simulações computacionais com o propósito de possibilitar o conflito cognitivo durante o processo de simulação em programas de simulação, uma vez que nesse programa é possível que o aluno altere parâmetros e variáveis podendo visualizar na hora as consequências dessas mudanças (TAO; GUNSTONE, 1999). Na química, assim como na física, o P.O.E vem sendo utilizado com a intenção de contribuir 
para a investigação de conceitos (BALEN; NETZ, 2005; SANTOS; GRECA, 2005; DORNELES et al., 2006) e pode ser utilizada como um recurso didático nas atividades experimentais (OLIVEIRA, 2003) para auxiliar na construção do conhecimento, uma vez que os alunos podem alterar os parâmetros e variáveis, ou seja, eles podem mudar a ordem do pensamento ou até mesmo o caminho a ser seguido.

A metodologia P.O.E. é dividida em três etapas ou passos (OLIVEIRA, 2003): (i) predizer: etapa em que os alunos vão discutir e resolver entre eles como vão resolver o problema proposto e conduzir a experimentação, ou seja, eles vão predizer o que esperam encontrar como resultado; (ii) observar: etapa em que o experimento é realizado e é observado o que acontece; (iii) explicar: etapa em que mediante ao que foi proposto incialmente e observado, todos os resultados encontrados serão explicados, verificando se o objetivo, ou seja, se o problema que foi proposto, foi resolvido.

A segunda proposta é a metodologia de investigação orientada por argumentos, do inglês Argument-DrivenInquiry (ADI). Esse modelo tem como ponto central a argumentação e o papel do argumento na construção social do conhecimento científico (WALKER; SAMPSON, 2013a) ao mesmo tempo em que possibilita a investigação. 
A metodologia ADI foi implementada em cursos de graduação em química com o intuito de melhorar tanto a argumentação verbal quanto a escrita. É baseada nas teorias da aprendizagem social construtivista (DRIVER et al., 1994; VYGOTSKY, 1978) e é projetada para tornar as aulas experimentais mais autênticas e educativas para os alunos (ANDERSON, 2007; BRANSFORD et al., 1999; DRIVER et al., 1994), uma vez que os alunos recebem o feedback no decorrer do processo e tem a oportunidade de aprender com os seus erros (WALKER, 2011).

É organizada em sete passos (Figura 1) que exigem que o aluno trabalhe em equipe a fim de desenvolver um procedimento para responder a uma determinada pergunta da pesquisa, seguido pela produção de um argumento inicial que articula e justifica uma explicação para o fenômeno sob investigação (argumento) (WALKER, 2011). 
Figura 1. Os sete passos do ADI

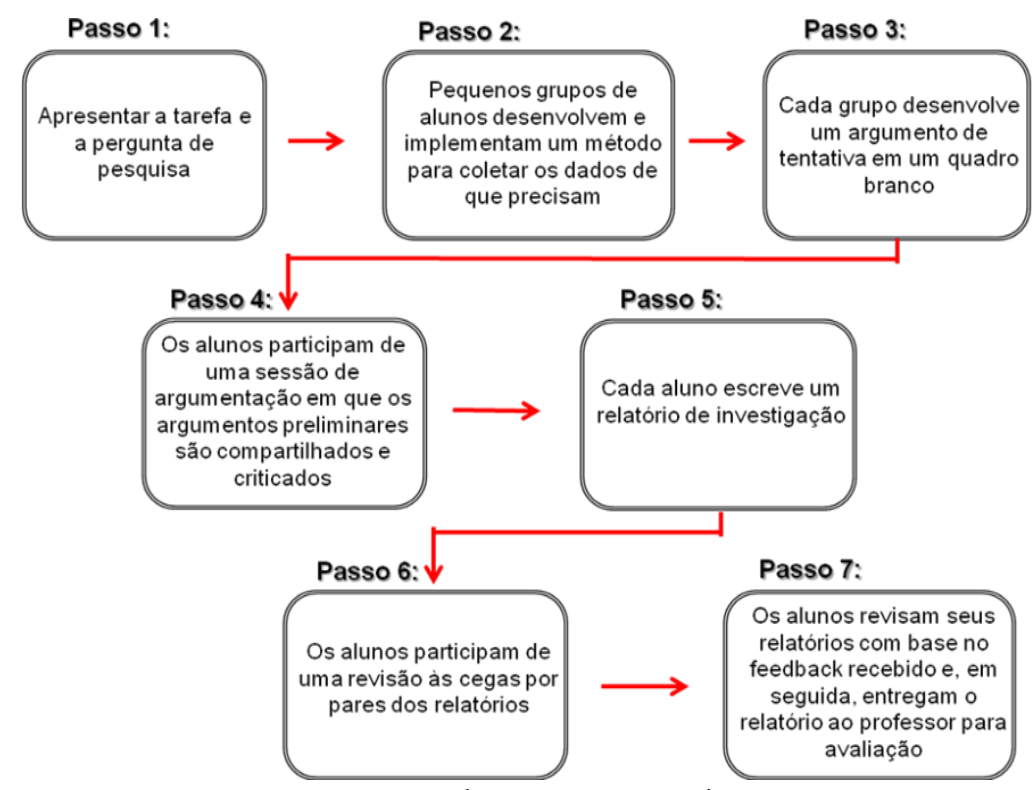

Fonte: (WALKER, 2011)

Diversos autores (DRIVER; NEWTON; OSBORNE, 2000;KUHN, 1993; NORRIS; PHILLIPS, 2003; SAMPSON; BLANCHARD, 2012;SIMON; ERDURAN; OSBORNE, 2006), vêm discutindo a necessidade de desenvolver argumentação nas aulas de ciências, considerando o fato de entender e elaborar argumentos como fundamental para o letramento científico, bem como, a capacidade de valorizar e favorecer o raciocínio crítico, contribuir para um maior entendimento dos conceitos (BELL; LINN, 2000; BERLAND; MCNEILL, 2011; ZOHAR; NEMET, 2002) e 
possibilitar aos alunos um maior entendimento da atividade e da natureza da Ciência (MILLAR; OSBORNE, 1998). E no Brasil, não é diferente; existem vários trabalhos sendo desenvolvidos sobre o assunto (SUART; MARCONDES, 2009; SÁ; QUEIROZ, 2011; OLIVEIRA; BATISTA; QUEIROZ, 2010) e "que são apresentados de várias maneiras, seja nos objetivos da pesquisa, ou nas escolhas dos referenciais para sustentarem as metodologias" (SCARPA, 2015 p.18).

Para Kuhn (1993), a argumentação deveria estar inserida nos contextos da sala de aula no dia a dia, para que o estudante pudesse perceber que o conhecimento pode ser contemplado como um processo constante de avaliação, onde as constantes modificações de conclusões se devem ao fato do surgimento de novos dados e argumentos, e não uma troca de concepção.

Costa (2008) destaca como motivo para o uso do ensino argumentativo em sala de aula, o fato de a aprendizagem ser um processo de construção do conhecimento, bem como no meio científico, em que são formuladas teorias para explicação de fenômenos. Essas teorias são abertas à refutação de outras pesquisas e outras teorias, permitindo a evolução da Ciência através de discussões, novos argumentos e conflitos. O autor destaca ainda, que investigações têm apontado que a argumentação válida não surge naturalmente, mas que é 
obtida na prática, por isso a necessidade de desenvolvê-la mais constantemente em sala de aula.

Apesar dos benefícios da argumentação científica, pesquisas apontam que muitos professores de ciências se mostram resistentes a uma nova metodologia. Os docentes também alegam falta de tempo para esse tipo de atividade, já que teriam que ensinar o aluno a escrever um texto argumentativo e isso tomaria mais tempo do pouco tempo que se tem para passar o conteúdo que é exigido pelo currículo. Esse dilema contribui para que os estudantes apresentem dificuldades em compartilhar suas ideias, em utilizarem dados para comprovação de hipóteses e relacionarem evidência e teoria (KELLY et al., 2008 apud SAMPSON et al., 2013; GALBRAITH e TORRANCE, 1999; HOLLIDAY; YORE; ALVERMANN, 1994 apud SAMPSON et al., 2013; SÁ e QUEIROZ, 2009).

Autores como Berland e Reiser (2009) defendem que a explicação e argumentação são técnicas complementares e muitos pesquisadores as tratam como única, já que são interligadas epistemicamente e constituem um gênero comunicativo específico. Por outro lado, alguns autores consideram que essa junção pode provocar dúvidas sobre o que seria explicação e o que seria argumento. Autores como, Braaten e Windschitl (2011) alertam sobre a dificuldade que professores de ciências encontram em diferenciar explicação de 
argumentação quando o objetivo é focar em uma dessas práticas.

Uma forma de compreender a diferença entre explicação e argumento é que, as condições que tornam algo uma boa explicação nem sempre geram condições para se ter um argumento válido. A explicação tem como objetivo entender o motivo pelo qual determinado fenômeno acontece, enquanto o argumento seria o ato de convencer alguém de que a sua hipótese está correta (BRIGANDT, 2016).

Um dos modelos mais estudados para análise de um argumento é o modelo de Toulmin (1958), que auxilia na avaliação da argumentação científica produzida pelos estudantes no ensino de ciências. $\mathrm{O}$ modelo considera que existem três elementos fundamentais a serem considerados para análise de um argumento: o dado (D), a justificativa (J), e a conclusão (C). Logo, podemos explicar um argumento da seguinte forma: "a partir de um dado $\mathbf{D}$, desde que a justificativa $\mathbf{J}$, então se chega à conclusão C". Porém, existem ainda outros dois elementos que podem ser acrescentados para que o argumento seja mais completo, que são: os qualificadores modais (Q), e, as condições de refutação (R), de modo a tornar aceitável determinada justificativa, oferecendo, então, suporte à conclusão. Com isso, tanto os qualificadores modais como a refutação, limitam a 
justificativa e acrescentam a relação entre os dados e as conclusões (SÁ; QUEIROZ, 2007).

A justificativa ainda pode ser apoiada em uma explicação fundada em um conhecimento de caráter teórico, chamada de conhecimento básico (B). O modelo padrão do argumento de Toulmin é apresentado na Figura 2.

Figura 2. Padrão argumentativo de Toulmin (1958).

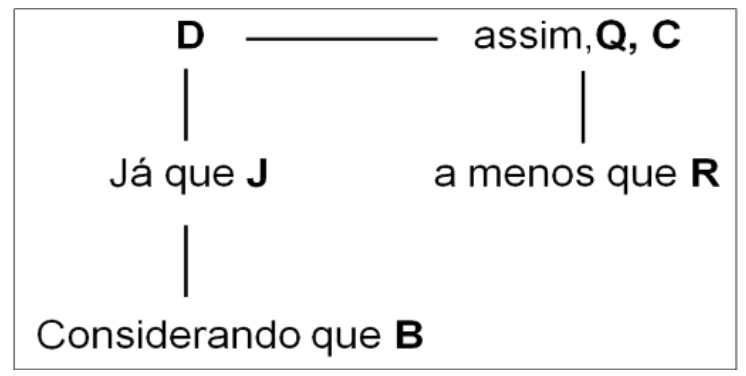

Fonte: Adaptado pela autora.

A partir das concepções e aportes teóricos apresentados até o momento, foi promovida a adaptação didática de alguns conteúdos destinados ao ensino de química na educação básica, tendo como alicerce a implementação da experimentação aliada a adaptação de roteiros pela metodologia ADI. Neste texto descrevemos as etapas de construção desse material e apresentamos uma análise da argumentação dos estudantes que o 
utilizaram, tendo como referência o modelo de Toulmin (1958).

\section{Desenvolvimento: Adaptações de aulas experimentais de química para o ensino básico}

Metodologicamente a pesquisa foi desenvolvida na perspectiva da análise qualitativa. Buscou-se investigar, a viabilidade da implantação da experimentação e a aplicabilidade da metodologia do ADI para a produção de roteiros de atividades práticas não reprodutivas para a educação básica, bem como o favorecimento da argumentação científica oral e escrita a partir dessa vivência.

Para tanto, foram produzidos dois roteiros experimentais adaptados com a metodologia ADI para implementação em sala de aula com estudantes do Ensino Médio de uma escola pública do município do Rio de Janeiro - RJ e estudantes do Ensino Fundamental II de uma escola privada do Rio de Janeiro - RJ, respeitando-se os conteúdos de cada série trabalhada. As adaptações realizadas nesses roteiros, bem como sua utilização nas atividades práticas, respeitaram todos os passos previstos para a metodologia ADI (Figura 1).

O roteiro adaptado para aplicação no Ensino Médio foi utilizado como atividade piloto na turma de $2^{0}$ 
ano com 30 alunos, e envolveu conceitos relacionados ao tema de Soluções. Para a execução dessa atividade piloto foram destinados 150 minutos - três tempos de 50 minutos. O registro de todo o processo foi realizado através de filmagem e gravação de áudio para posterior análise. Nessa atividade piloto com a turma do Ensino Médio, o foco principal foi analisar a implementação da experimentação e dos roteiros adaptados para seu desenvolvimento, sem o foco da análise da argumentação.

A professora responsável pela turma informou que seria a primeira vez que a turma participaria de uma aula prática na sala de aula. A partir da realização do experimento adaptado pela metodologia ADI foi possível realizar uma análise do seu desenvolvimento e levantar alguns pontos importantes:

- Dos cinco grupos criados, apenas um discutiu previamente e analisou as possibilidades antes de iniciar o experimento, ou seja, apenas um grupo praticou o passo 2 do ADI;

- Por conta de feriado e semana de provas, a segunda aula dedicada a esta atividade só pôde acontecer duas semanas após a primeira, desarticulando o foco da atividade; 
- Dos trinta estudantes, somente oito entregaram os relatórios, ou seja, somente oito estudantes cumpriram o passo 5 do $\mathrm{ADI}$;

- Após a avaliação dos relatórios às cegas feita pelos próprios estudantes - passo 6 do ADI - os estudantes se negaram a promover as modificações sugeridas pelos demais colegas - passo 7 do ADI alegando que as modificações não eram pertinentes e sim pessoais (como foram entregues poucos relatórios, é possível que tenham identificado o autor e o avaliador). Um único aluno aceitou corrigir o relatório, porém acabou não realizando a entrega final à professora;

- Os estudantes nunca haviam confeccionado nenhum tipo de relatório; a maioria dos estudantes apenas escreveu o desenvolvimento da atividade sem qualquer explicação;

- Dos sete relatórios entregues, somente três eram diferentes uns dos outros, ou seja, individuais como proposto no passo 5 do ADI.

Levando-se em consideração os pontos observados e as dificuldades encontradas pela docente pesquisadora e pelos estudantes, foram realizados ajustes nos roteiros, no tempo para a sequência de desenvolvimento das atividades e nas estratégias para aplicação da experimentação pela pesquisadora. 
Além disso, devido à dificuldade de continuidade das atividades na mesma escola, a pesquisa passou a contar apenas com a participação da turma do $9^{\circ}$ ano do Ensino Fundamental II, com 11 estudantes, em uma escola privada e envolveu conceitos relacionados à Separação de Misturas.

Para a execução da atividade piloto com esta turma do Ensino Fundamental II foram destinados 270 minutos - seis tempos de 45 minutos cada. A atividade teve duração de três semanas consecutivas. Foi analisado a aplicabilidade dos roteiros adaptados e o desenvolvimento argumentativo. Com a aplicação da atividade piloto nessa turma foi possível observar alguns pontos:

- Inicialmente os estudantes não estavam dispostos a refletir e anotar, o que foi resolvido com alguma explicação sobre a importância dessa etapa (passo 2 do ADI);

- Na etapa de argumentação (passo 4 do ADI) foi possível observar que apenas um dos três grupos formados estava de fato participando; porém os estudantes se detiveram a explicar como conseguiram resolver o problema e por que tinham seguido aquele raciocínio. A estratégia nesse momento foi realizar algumas intervenções incentivando os estudantes a 
falarem mais e a questionarem uns aos outros. Houve uma maior fluidez da etapa o que nos sugere que talvez os estudantes não soubessem como desenvolver essa etapa sem essas poucas orientações;

- Somente três alunos, do total de onze entregaram os relatórios (passo 5 do ADI). A estratégia adotada pela docente pesquisadora foi de levar a turma para sala de informática para que todos confeccionassem o relatório já que a etapa seguinte (etapa 6) dependia dessa confecção. Os estudantes que já haviam cumprido essa etapa, puderam rever e promover modificações.

- No passo 6 do ADI, foi possível observar um certo desconforto sobre o fato de estarem "corrigindo" os colegas. Por ser uma turma pequena, e se conhecerem bem, era fácil identificar os autores e avaliadores dos relatórios. Um grupo não participou da atividade como os demais. O grupo apresentou o mesmo comportamento durante a realização do experimento, com apenas um de seus integrantes realizando as etapas praticamente sozinho. O grupo modificava o comportamento apenas com a aproximação da pesquisadora.

- Três estudantes não concordaram com as orientações dos colegas para correções e adequações nos relatórios;

Destacamos ainda que apesar desses estudantes participarem de aulas em laboratório, eles nunca tinham 
trabalhado com uma metodologia em que estivessem livres para fazerem as escolhas e tomarem as decisões, bem como discutirem os resultados com os colegas, e ainda, sugerirem correções. E ainda, que os estudantes não haviam tido contato com alguns conteúdos e conceitos científicos que contribuiriam para algumas possíveis explicações e justificativas mais consistente de suas observações e hipóteses.

Terminada essa etapa piloto de desenvolvimento da atividade prática pela metodologia adaptada com a turma do Ensino Fundamental II, iniciou-se a etapa de verificação e análise da argumentação produzida por esses estudantes, especialmente a oral.

Destacamos uma sequência da transcrição do áudio (Tabela 1) que exemplifica a análise pelo padrão de Toulmin (1958). Nessa sequência a pesquisadora (P) interage com os estudantes do Grupo B acerca de um dos procedimentos adotados por eles para separação de uma mistura composta por água + areia + limalha de ferro.

Tabela 1: Sequência transcrita acerca dos procedimentos adotados para separação de uma mistura por um dos grupos de estudantes.

\begin{tabular}{c|l|c} 
Turnos & \multicolumn{1}{|c|}{ Falas } & $\begin{array}{c}\text { Argumento } \\
\text { Padrão }\end{array}$ \\
\hline 6 & P: Mas por que você vai usar o imã? & Conclusão \\
\hline 7 & $\begin{array}{l}\text { B1: Para separar a limalha de ferro. (so- } \\
\text { brenadante) }\end{array}$ & Dado \\
\hline 8 & P: E aí você está tentando tirar agora? &
\end{tabular}




\begin{tabular}{c|l|l} 
& $\begin{array}{l}\text { Será que você vai conseguir separar } \\
\text { agora? (a mistura ainda continha areia e } \\
\text { água) }\end{array}$ & \\
\hline 9 & B2: Estamos tentando. & \\
\hline 10 & $\begin{array}{l}\text { P: Mas será que não tem limalha lá no } \\
\text { fundo? }\end{array}$ & $\begin{array}{l}\text { B2: (pensando) Por que tem que compli- } \\
\text { car minha vida? }\end{array}$ \\
\hline 12 & B3: O que foi? & $\begin{array}{l}\text { P: A aluna B2 me disse que vocês estão } \\
\text { tentando tirar a limalha que está "boian- } \\
\text { do", aí eu questionei se toda a limalha } \\
\text { estaria "boiando" ou se poderia ter lima- } \\
\text { lha no fundo, junto com a areia. }\end{array}$ \\
\hline 14 & $\begin{array}{l}\text { B3: Pera, pera, pera... } \\
\text { (nesse momento B3 pegou o copo e o imã } \\
\text { e colocou o imã próximo ao fundo do co- } \\
\text { po onde tinha areia) }\end{array}$ & $\begin{array}{l}\text { Justificativa } \\
\text { É, dá pra sentir que tá puxando, eu pen- } \\
\text { so demais. }\end{array}$
\end{tabular}

Fonte: Autores

Segundo o padrão de Toulmin, para ser considerado um argumento, é preciso que a estrutura apresente os três elementos fundamentais do argumento, que são: Dado, Conclusão e Justificativa. Dessa forma, o trecho anterior trazido como exemplo, pode ser considerado como um argumento, apesar dos estudantes não terem apresentado uma justificativa mais aprofundada do porquê usar o imã. A Figura 3 estrutura a análise realizada do trecho selecionado. 
Figura 3: Argumento do grupo B para separar a limalha de ferro dos demais materiais.

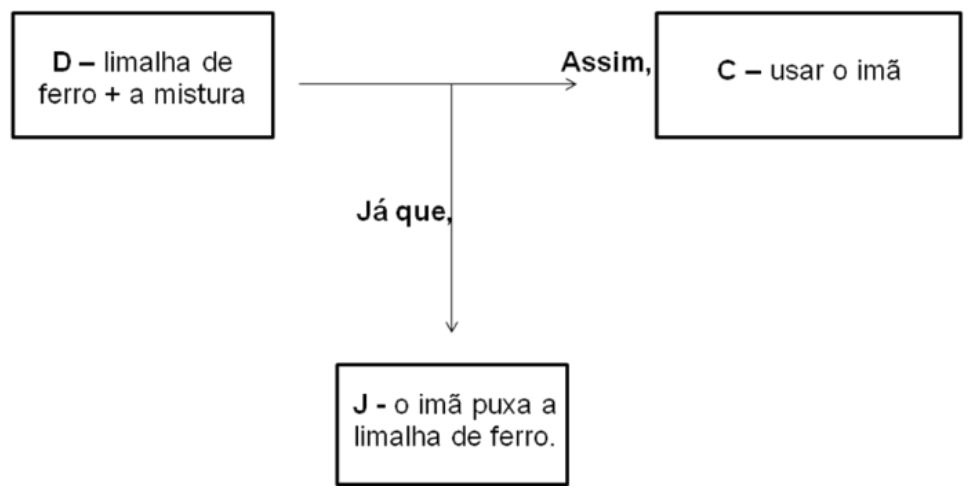

Fonte: Adaptado pelos autores

Apesar da sequência apresentada, de modo geral, para essa aplicação piloto, a análise revelou que a maioria dos estudantes faziam uso, de apenas dois, dos três, elementos básicos de um argumento: o dado e a conclusão. Essa observação foi importante para que pudéssemos levantar algumas hipóteses do motivo pelo qual eles não justificavam suas conclusões, mesmo tendo sido orientados para isso; uma hipótese foi a possibilidade de terem considerado algumas justificativas "muito óbvias", e que, portanto, não se fariam necessárias. Por exemplo, se a mistura contém limalha de ferro e o imã atraí o ferro, pode não se fazer necessário justificar a escolha pela separação magnética (uso do imã). 
Tendo colecionado todas as observações, análises e avaliações da pesquisa, possibilitadas pelas duas aplicações piloto (turma do $2^{\mathrm{O}}$ ano do Ensino Médio e turma do $9^{\circ}$ ano do Ensino Fundamental II), e ainda considerando a necessidade de ajuste de tempo (de três para dois dias - três tempos), e, ajuste na introdução para que esta se aproximasse de situações cotidianas ou que pudessem ser contextualizadas ao contexto regional, foi realizado uma última adaptação nesse mesmo roteiro sobre Separação de Misturas. Transcorridos cinco meses, essa mesma atividade prática foi novamente proposta para a turma do $9^{\circ}$ ano do Ensino Fundamental II, com 11 estudantes.

Assim como anteriormente, a turma foi dividida em grupos (dois grupos) e foram entregues os roteiros e os materiais; o roteiro foi todo lido e atendidas possíveis dúvidas iniciais (Passo 1). Em seguida, eles iniciaram a atividade com a discussão de qual a melhor maneira para a realização do experimento (Passo 2) e explicação dos resultados que estavam sendo encontrados (Passo 3). Já nesse momento foi possível observar que os grupos se preocuparam em discutir o que pretendiam fazer com mais atenção e analisando todas as possibilidades antes de iniciarem o experimento, ou seja, como esse tipo de atividade e metodologia já havia sido utilizada na etapa piloto, os estudantes foram mais proativos. 
A análise das transcrições dos passos 2 e 3 nos permitiu observar poucos trechos contendo argumentos considerados mais completos, ou seja, com mais elementos do modelo de Toulmin, tendo sido mais comum os argumentos com apenas os três elementos padrões (dado, conclusão, justificativa). A Tabela 2 evidencia um trecho onde é possível apontar um argumento mais completo.

Tabela 2: Trecho da conversa do grupo B.

\begin{tabular}{c|l|c} 
Turnos & \multicolumn{1}{|c|}{ Falas } & Padrão Argumentativo \\
\hline 1 & P: O que vocês vão fazer? & Questão \\
\hline 2 & $\begin{array}{l}\text { B1: A gente vai colocar areia, } \\
\text { serragem e pedra e vai botar } \\
\text { na peneira }\end{array}$ & Dado/conclusão \\
\hline 3 & $\begin{array}{l}\text { B2: e se não der a areia com a } \\
\text { peneira, eu vou colocar ela no } \\
\text { filtro de papel. A água vai } \\
\text { restar e a limalha de ferro } \\
\text { vamos tirar com o imã. }\end{array}$ & Justificativa/refutação \\
\hline 4 & P: E aí vocês vão conseguir & Questão \\
\hline 5 & B2: É. &
\end{tabular}

Fonte: Elaborado pelos autores

Nesse trecho é possível observar que além dos três elementos básicos do modelo de Toulmin (dado, conclusão, justificativa), encontra-se um quarto elemento - a refutação - o que torna esse argumento mais completo quando comparado aos demais. A Figura 4, exemplifica a estruturação da argumentação a partir desses elementos. 
Figura 4: Argumento do grupo B para separar a mistura.

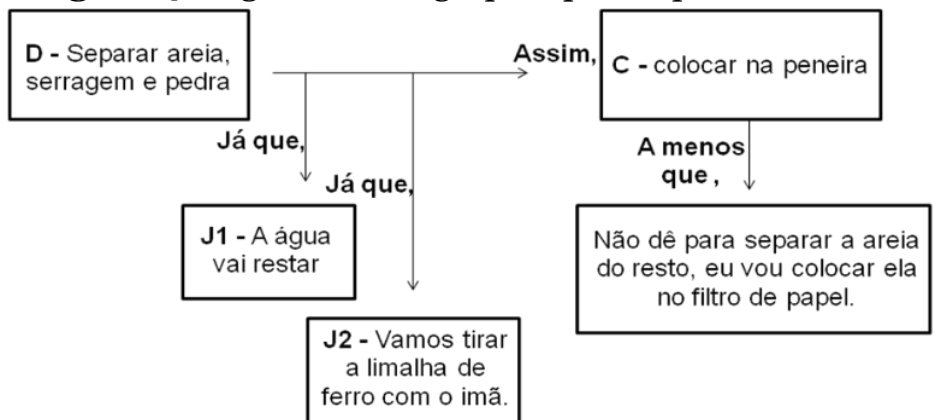

Fonte: Elaborado pelos autores

Na etapa da sessão de argumentação (Passo 4), os dois grupos trocaram informações entre si, ideias e explicações no intuito de convencer os colegas que a solução encontrada pelo grupo foi a melhor. A mediação pela pesquisadora foi realizada quando necessário e em geral foi incentivando para que exercitassem a fala. A Tabela 3 exemplifica o desenvolvimento dessa etapa de argumentação.

Tabela 3: Trecho da sessão de argumentação

\begin{tabular}{|c|c|c|}
\hline Turnos & Falas & $\begin{array}{l}\text { Argumento } \\
\text { Padrão }\end{array}$ \\
\hline 1 & $\begin{array}{l}\text { B2: Primeiro a gente discutiu o } \\
\text { que ia fazer, a gente foi fazendo } \\
\text { as etapas. Primeiro a gente tirou a } \\
\text { parte líquida da parte sólida, a } \\
\text { parte mais densa, usando o papel } \\
\text { de filtro e funil e aí a gente } \\
\text { conseguiu. Sobrou o mel, a areia e } \\
\text { as pedras. O segundo passo foi }\end{array}$ & Dado/conclusão \\
\hline
\end{tabular}




\begin{tabular}{|c|c|c|}
\hline & $\begin{array}{l}\text { tirar as pedras, aí a gente usou o } \\
\text { método da catação. Aí sobrou a } \\
\text { areia e o mel e aí ficamos um } \\
\text { tempinho pensando como a gente } \\
\text { ia separar a areia do mel, porque } \\
\text { eles estavam juntos, e aí a gente } \\
\text { tentou usar o método da } \\
\text { peneiração. }\end{array}$ & \\
\hline 2 & B4: Sem a água. & \\
\hline 3 & $\begin{array}{l}\text { B2: É, a primeira vez foi sem a } \\
\text { água, a gente jogou a areia com o } \\
\text { mel na peneira e deixou cair e aí } \\
\text { vimos que na peneira ainda tinha } \\
\text { um pouquinho de mel com a areia, } \\
\text { mas tinha mais areia que mel. Aí } \\
\text { depois a gente resolveu jogar um } \\
\text { pouco de água para ver se o mel } \\
\text { saia; e a gente conseguiu. }\end{array}$ & \\
\hline 4 & $\begin{array}{l}\text { A5: A gente recebeu o nosso pote } \\
\text { com álcool, areia, mel e pedra e } \\
\text { até então eles não eram solúveis, } \\
\text { porque não se misturavam. }\end{array}$ & \\
\hline 5 & $\begin{array}{l}\text { A2: Então a gente decidiu usar o } \\
\text { funil de separação para poder } \\
\text { separar a parte menos densa da } \\
\text { parte mais densa que seria o } \\
\text { álcool do mel. A gente conseguiu } \\
\text { separar o álcool, aí ficou o mel, } \\
\text { areia... }\end{array}$ & $\begin{array}{l}\text { Dado/conclusão/ } \\
\text { justificativa }\end{array}$ \\
\hline 6 & $\begin{array}{l}\text { A5: E só. } \\
\text { Fonte: Elaborado pelos autor }\end{array}$ & \\
\hline
\end{tabular}


Esse trecho revela a presença de dois argumentos; um deles tem a justificativa de forma implícita, conforme mostrado nas Figuras 5 e 6:

Figura 5: Argumento do grupo B para separar as pedras dos demais materiais.

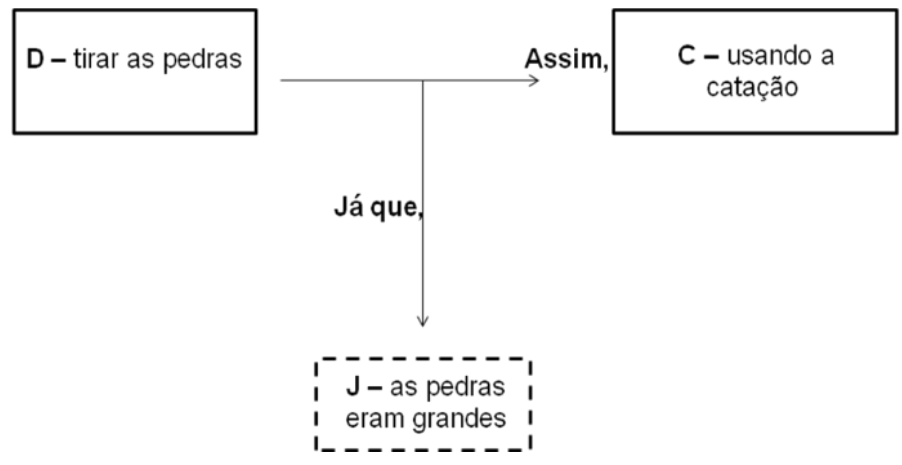

Fonte: Elaborado pelos autores

Figura 6: Argumento do grupo A para separar o álcool (água) do mel.

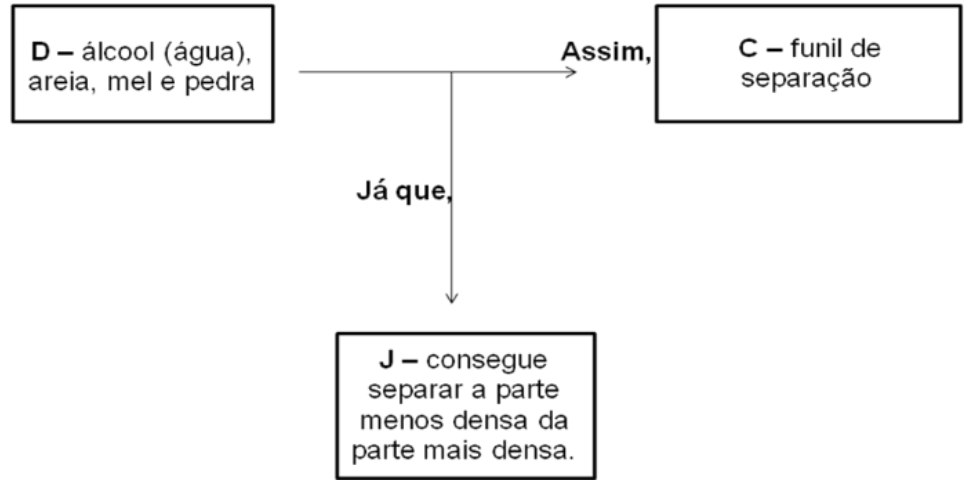

Fonte: Elaborado pelos autores 
Observa-se que os dois argumentos, seguem o modelo de argumento padrão de Toulmin (1958), ainda que um deles apresente uma justificativa implícita.

Com a entrega dos relatórios (Passo 5) foi possível realizar a revisão às cegas pelos colegas (Passo 6). Nessas duas etapas, houve, tal qual na realização das versões piloto, certa dificuldade com a continuidade da pesquisa, visto que somente seis estudantes compareceram à aula prevista para essa etapa, situação que foge ao controle e previsão do desenvolvimento das atividades, e, somente cinco dos estudantes entregaram os relatórios. Apesar disso, foi dada continuidade à atividade e os estudantes realizaram o Passo 6 de avaliação dos relatórios. A avaliação é desenvolvida pelos próprios estudantes, às cegas, com ajuda de um guia préestabelecido para essa etapa. Na sequência, os estudantes decidem se vão ou não acatar as sugestões e promovem as alterações necessárias em seus relatórios (Passo 7).

A análise dos relatórios nos permite observar o desenvolvimento das justificativas para as evidências encontradas e possíveis conexões com a conclusão e o próprio desenvolvimento da argumentação. Para essa avaliação escrita, analisamos o preenchimento do quadro proposto no Passo 3, cujas transcrições do preenchimento realizado pelos Grupos A e B são mostradas nos Quadros 1e 2, respectivamente. 
Quadro 1: Quadro preenchido pelo Grupo A.

A questão orientadora: "É possível separar a mistura de mel, areia, corante, álcool?"

Nossa conclusão: "Usamos os métodos mais eficientes, foram: filtração, catação e funil de separação".

\section{Nossas evidências:}

“A mistura é heterogênea".

"O mel é mais denso que o álcool”.

"A areia juntou, mas não solidificou com o mel”.

“Elas não são solúveis”.

\section{Nossas justificativas das evidências:}

"Nós observamos mais de uma fase".

“Encontra-se abaixo do álcool”.

"Pois o mel é denso e grudento".

“Pois não se misturaram”.

Fonte: Elaborado pelos autores

Quadro 2: Quadro preenchido pelo Grupo B

A questão orientadora: "Como separar uma mistura?"

Nossa conclusão: "Conseguimos tudo o que discutimos, e foi realizado com sucesso, porém a última etapa não foi concluída completamente. O mel não foi totalmente separado da areia".

Nossas evidências:

"A mistura heterogênea que foi apresentada tinha 3 fases não solúveis a água”.
Nossas justificativas das evidências:

"A mistura era heterogênea, pois possuía mais de uma fase. Eram insolúveis porque conseguimos ver cada uma das fases resultantes (mel, areia, pedra e álcool)”.

Fonte: Elaborado pelos autores 
Ao avaliar o preenchimento dos quadros pelos grupos (Passo 3) em comparação à escrita apresentada nos relatórios, percebe-se que as evidências e as justificativas das evidências que cada grupo discutiu e apresentou no quadro durante a realização do experimento, não são apresentadas nos relatórios individuais entregues (Passo 5), não tendo sido levados em consideração no momento de sua confecção. Observase que os estudantes acabam por descartar dados relevantes ou evidências que seriam importantes para o detalhamento dos métodos adotados e observações feitas. De modo geral, esses detalhamentos poderiam contribuir para melhor confecção dos relatórios escritos, melhor desenvolvimento do Passo 6 (avaliação às cegas), mas principalmente, para o melhor desenvolvimento da argumentação científica que envolve o experimento.

\section{Considerações finais}

A vivência dessa pesquisa, que promoveu a inserção de aulas práticas de química na educação básica, com roteiros adaptados pela metodologia ADI, nos possibilita algumas considerações.

A análise dos dados mostrou avanços positivos no desenvolvimento dos estudantes a partir da adaptação e utilização dessa metodologia na educação básica. Percebe-se que a construção dos argumentos e suas 
justificativas se modificaram entre as etapas piloto e a etapa final de aplicação, apresentando maior qualidade a partir do padrão de Toulmin. A mesma observação pode ser feita para a etapa de participação de correções as cegas dos relatórios dos colegas, que ao longo do processo foi se tornando menos desconfortável para os estudantes, e, que também ajudou no exercício de justificativa dos argumentos. A escrita e entrega dos relatórios, foi um ponto que precisou de mais atenção ao longo de todas as aplicações da atividade. De modo geral, os estudantes apresentaram bastante resistência a esta etapa e adaptações precisaram ser realizadas - como por exemplo, conduzir os estudantes até a sala de informática para confecção dos relatórios - para que o andamento do processo da atividade não ficasse prejudicada como um todo, bem como, para que pudéssemos concluir etapas da análise da pesquisa. Foi possível constatar ainda, tal qual amplamente descrito na bibliografia, que os estudantes têm dificuldade em lidar com o protagonismo que metodologias ativas, dialógicas e investigativas ofertam; esse estranhamento e dificuldade pode ser justificado pelo próprio desenvolvimento do cenário educacional do país, que culmina na figura do professor como sendo o responsável pelo repasse dos conhecimentos e os estudantes apenas os recebem.

A vivência da pesquisa também nos permite afirmar que, apesar de todo planejamento e adaptações que são necessárias para a implantação das atividades 
práticas, nem sempre a experimentação acontecerá conforme o esperado, já que cada turma responde e reage de forma diferente em relação ao que difere do comum. Nesse sentido, torna-se importante o conhecimento experiencial do professor, que vai sendo adquirido a cada atividade vivenciada, bem como sua capacidade de autoavaliação e atuação como professor-mediador nas aulas. $\mathrm{Na}$ mediação, o professor passa a dividir o protagonismo com os estudantes, exercendo um papel fundamental de contribuir para que os estudantes desenvolvam suas habilidades cognitivas e argumentativas.

Também foi possível constatar que a aceitação e os resultados esperados para este tipo de atividade ou metodologia, serão mais eficientes no sentido práticocognitivo, ao se tornar uma prática cotidiana da vida escolar, e não apenas se configurando como atividades isoladas ao longo do ano com função demonstrativa de conteúdos e conceitos.

A pesquisa nos permite contribuir para o ensino de ciências e de química ao favorecer a possibilidade de proposição e a compreensão de conflitos cognitivos por meio de uma abordagem didática de cunho dialógico e aberto, que favorece a investigação, a tomada de decisão e ajuda na formação do pensamento crítico do estudante, além de romper com o método tradicional de ensino, 
onde o estudante só responde ou questiona quando incitado a isso.

Por fim, esse trabalho resultou na elaboração de um material de apoio para professores que desejarem adaptar a metodologia para suas salas de aula. Esse material, que contém informações e instruções para elaboração e adaptação de roteiros para atividades práticas, bem como exemplos de roteiros já adaptados, pode ser utilizado tanto em sala de aula quanto nos laboratórios destinados às aulas de ciências (ARAUJO et al, 2021).

\section{Referências}

ANDERSON, C. Perspectives on Science Learning. In S. K. Abell \& N. Lederman (Eds.), Handbook of research in science education. Mahwah, NJ: Lawrence Erlbaum Associates, p. 330, 2007.

ARAUJO, Y. L. N.; Moreira, L. M.; Milanez, J. Adaptações de Aulas Experimentais de Química para o Ensino Básico: Material para Professores. Disponível em: <http://educapes.capes.gov.br/handle/capes/586097>. 2021.

BALEN, O.; NETZ, P. A. Modelagem e Simulação Computacional no Estudo de Gases Ideais e Reais, Acta Scientiae, v. 7, $\mathrm{n}^{0}$ 2, 2005.

BARBERÁ, O; VALDÉS, P. El trabajo práctico em la ensenãnza de las ciencias: una revisión. Ensenãnza de las Ciencias, 
Investigacion y Experiências Didacticas. v. $14, \mathrm{n}^{0}$ 3, p. 365379, 1996.

BELL, P.; LINN, M. C. Scientific arguments as learning artifacts: designing for learning from the web with KIE. International Journal of Science Education, Abingdon, v. 22, $\mathrm{n}^{\mathrm{o}} .8$, p. 797-817, 2000.

BERLAND, L. K.; MCNEILL, K. L. A learning progression for scientific argumentation: understanding student work and designing supportive instructional contexts. Science Education, Hoboken, v. 94, no . 5, p. 765-793, 2011.

BERLAND, L. K.; REISER, B. J. Making sense of argumentation and explanation. Science Education, Hoboken, v. $93, \mathrm{n}^{\mathrm{o}} .1, \mathrm{p} .26-55,2009$.

BRANSFORD, J.; BROWN, A.; COCKING, R. How people learn: Brain, mind, experience and school. Washington, DC: National Academy of Science Press, p. 386, 1999.

BRAATEN, M.; WINDSCHITL, M. Working toward a stronger conceptualization of scientific explanation for science education. Science Education, Hoboken, v. 95, no. 4, p. 639669, 2011.

BRIGANDT, I. Why the difference between explanation and argument matters to science education. Science \& Education, Dordrecht, v. 25, nº. 1, p. 251-275, 2016.

COSTA, A. Desenvolver a capacidade de argumentação dos estudantes: um objetivo pedagógico fundamental. Revista Iberoamericana de Educación, v. 46, nº 5, 2008.

DORNELES, P. F. T.; ARAÚJO, I. S.; VEIT, E. A. Simulação e Modelagem Computacionais no Auxílio à Aprendizagem 
Significativa de Conceitos Básicos de Eletricidade: Parte I circuitos elétricos simples. Rev. Bras. Ens. Fís. V. 28, no ${ }^{\mathrm{o}}$ 4, p. 487-496, 2006.

DRIVER, R.; ASOKO, H., LEACH, J.; MORTIMER, E.; SCOTT, P. Constructing scientific knowledge in the classroom. Educational Researcher, $v .23, n^{o} .7$, p. 5-12, 1994.

DRIVER, R.; NEWTON, P.; OSBORNE, J. Establishing the norms of scientific argumentation in classrooms. Science Education, Hoboken, v. 84, no .3 , p. 287-312, 2000.

FRASER, B. J.; TOBIN, K.G. (eds.) International Handbooks of Science Education. London: Kluber Academic Publishers. P. $1271,1998$.

GABEL, D.L. (Ed.). Handbooks of Research on Science Teaching and Learning. New York: Macmillan Pub.Co. 1994.

GALBRAITH, D.; TORRANCE, M. (Eds.). Knowing what to write: Conceptual processes in text production. Amsterdam, The Netherlands: Amsterdam University Press, p. 190, 1999.

GALIAZZI, M. do C.; ROCHA, J. M. de B.; SCHMITZ, L. C.; SOUZA, M. L. de; GIESTA, S.; GONÇALVES, F. P. Objetivos das Atividades Experimentais no Ensino Médio: A Pesquisa Coletiva Como Modo de Formação de Professores de Ciências. Ciência \& Educação, v.7, nº.2, p.249-263, 2001.

JIMÉNEZ-ALEIXANDRE, M. P.; ERDURAN, S. Argumentation in science education: an overview. In: ERDURAN, S.; JIMÉNEZ-ALEIXANDRE, M. P. (Ed.). Argumentation in science education. Dordrecht: Springer, $\mathrm{p}$. 3-27, 2007. 
KELLY, G., REGEV, J.; PROTHERO, W. Analysis of lines of reasoning in written argumentation. In S. Erduran \& M. Jimenez-Aleixandre (Eds.), Argumentation in science education: Perspectives from classroom-based research. Dordrecht, The Netherlands: Springer, p. 137-157, 2008.

KUHN, D. Science as argument: implications for teaching and learning scientific thinking. Science Education, Hoboken, v. $77, \mathrm{n}^{\mathrm{o}} \cdot 3$, p. 319-337, 1993.

KYRIACOU, C., E COULTHARD, M. Undergraduates' views of teaching as a career choice. Journal of Education for Teaching, v. 26, $\mathrm{n}^{\mathrm{O}} .2$, p.117-126, 2000.

MILLAR, R.; OSBORNE, J. BEYOND 2000: Science education for the future. London: King's College London, School of Education, 1998.

NORRIS, S. P.; PHILLIPS, L. M. How literacy in its fundamental sense is central to scientific literacy. Science Education, Hoboken, v. 87, nº. 2, p. 224-240, 2003.

OLIVEIRA, P.R.S. A Construção Social do Conhecimento no Ensino-Aprendizagem de Química. In: Atas do IV Encontro Nacional de Pesquisa em Educação em Ciências (ENPEC), Bauru, SP, 2003.

OLIVEIRA, J. R. S. de; BATISTA, A. A.; QUEIROZ, S. L. Escrita científica de alunos de graduação em química: análise de relatórios de laboratório. Química Nova (Impresso), v. 33, p. 1980-1986, 2010.

SÁ, L. P.; QUEIROZ, S. L. Promovendo a argumentação no ensino superior de química. Química Nova (Impresso), v. 30, p. 2035-2042, 2007. 
O espaço para a argumentação no ensino superior de química. Educación Química, v. XX, n. 2, p. 104-110, 2009.

SAMPSON, V.; BLANCHARD, M. R. Science teachers and scientific argumentation: trends in views and practice. Journal of Research in Science Teaching, v. 49, $\mathrm{n}^{\mathrm{o}}$. 9, p. 1122-1148, 2012.

SAMPSON, V., ENDERLE, P., GROOMS, J.; WITTE, S. Writing to learn by learning to write during the school science laboratory: Helping middle and high school students develop argumentative writing skills as they learn core ideas. Science Education, v. 97, n. 5, p. 643-670, 2013.

SANTOS, F. M. T.; GRECA, I. M. Promovendo Aprendizagem de Conceitos e de Representações Pictóricas em Química com uma Ferramenta de Simulação Computacional. Rev. Elect. Ens. de las Ciencias, v. 4, $\mathrm{n}^{0} .1,2005$.

SCARPA, D. L. O papel da argumentação no ensino de ciências: lições de um workshop. Ensaio Pesquisa em Educação em Ciências, v. 17, p. 15-30, 2015.

SCHWAHN, M. C. A.; OAIGEN, E. R. O Uso do Laboratório de Ensino de Química como Ferramenta: investigando as concepções de licenciandos em Química sobre o Predizer, Observar, Explicar (POE). Acta Scientiae (ULBRA), v. 10, p. 151-159, 2008.

SIMON, S.; ERDURAN, S.; OSBORNE, J. Learning to teach argumentation: research and development in the science classroom. International Journal of Science Education, Abingdon, v. 28, $\mathrm{n}^{\mathrm{o}} .2-3$, p. 235-260, 2006.

SUART, R. C. A experimentação no ensino de química: Conhecimentos e caminhos. In: Santan, E; Silva, E. (Orgs) 
Tópicos em Ensino de Química. São Carlos, SP, Pedro \& João Editores, p. 63-88, 2014.

SUART, R. C.; MARCONDES, M. E. R. A argumentação em uma atividade experimental investigativa no ensino de química. In: VII Enpec, 2009, Florianópolis. Anais do VII Encontro de Pesquisa, 2009.

TAO, P.K., GUNSTONE, R.F. Conceptual Change in Science through Collaborative Learning at the computer. International Journal of Science Education. v. 21, nº. 1, p.39-57, 1999.

TOULMIN, S.E. The uses of argument. Cambridge: Cambridge University Press, p. 247, 1958.

VYGOTSKY, L. S. The development of higher psychological processes. Mind in society. Cambridge: Harvard University Press, 1978.

WALKER, J. P. Argumentation in Undergraduate Chemistry Laboratories. 2011. 118 f. Tese (Doutorado) - Philosophy Course, School of Teacher Education, Florida State University, Florida, 2011.

WALKER, J. P.; SAMPSON, V. Learning to argue and arguing to learn: Argument-Driven Inquiry as a way to help undergraduate chemistry students learn how to construct arguments and engage in argumentation during a laboratory course. Journal of Research in Science Teaching, v. 50, $\mathrm{n}^{\mathrm{O}} .5$, p. 561-596, 2013a.

Argument-Driven Inquiry: using the laboratory to improve undergraduates' science writing skills through meaningful science writing, peer-review, and revision. Journal of Chemical Education, v. 90, p. 1269-1274, $2013 \mathrm{~b}$. 
WELlington, J. (ed.) Practical Work in School Science. London: Routledge, p. 312, 1998.

ZOHAR, A.; NEMET, F. Fostering students' knowledge and argumentation skills through dilemmas in human genetics. Journal of Research in Science Teaching, Hoboken, v. 39, $\mathrm{n}^{\mathrm{o}}$. 1, p. 35-62, 2002. 